\title{
Power-based behaviors between supply chain partners of diverse national and organizational cultures: The crucial role of boundary spanners' cultural intelligence
}

\author{
William H. Murphy ${ }^{1}$, Ismail Gölgeci2\#, and David A. Johnston ${ }^{3}$ \\ ${ }^{1}$ Associate Professor of Marketing, Department of Management and Marketing, Edwards School \\ of Business, University of Saskatchewan, Room 151, PotashCorp Centre, 25 Campus Drive, \\ Saskatoon, Saskatchewan, Canada, S7N 5A7. Tel: +1 (306) 966-2769, e-mail: \\ wmurphy@edwards.usask.ca
}

${ }^{2}$ Dr, Associate Professor, School of Business and Social Sciences, Department of Business Development and Technology, Aarhus University, Birk Centerpark, Herning, 7400, Denmark. EMail: i.golgeci@,btech.au.dk

${ }^{3}$ Professor of Operations Management and Information Systems, Operations Management and Information Systems Area, Schulich School of Business, York University, Room S339, Toronto, Ontario, Canada M3J 1P3, Tel: +1 (416) 736-2100 Ext. 77950, Fax: +1 (416) 736-5687, e-mail: djohnston@schulich.yorku.ca

\section{\#Corresponding Author}

\begin{abstract}
Purpose- This paper explains the effects of national and organizational cultures of boundary spanners on their choices of using three archetype power-based behaviors - dominance, egalitarian, and submissive- with supply chain partners. Improved outcomes for GSC partners are anticipated due to the ways that cultural intelligence affects these culturally guided decisions.

Design/methodology/approach- Drawing on multiple streams of literature and focusing on boundary spanners in global supply chains, we build a conceptual framework that highlights cultural antecedents of predispositions toward power-based behaviors and explains the moderating role of cultural intelligence of boundary spanners on behaviors performed.

Findings- We propose that boundary spanners' national and organizational cultural values influence predispositions toward applying and accepting power-based behaviors. We also discuss how cultural intelligence moderates the relationship between culturally determined predispositions and power-based behaviors applied by partners. The cultural intelligence of boundary spanners is argued to have a pivotal role in making power-based decisions resulting in healthier cross-cultural buyer-supplier relationships.

Originality/value- Our paper is the first paper to advance an understanding of the cultural antecedents of boundary spanners' power-based behaviors that are exercised and interpreted by partners in global supply chains. Furthermore, the potential role of cultural intelligence in interorganizational power dynamics and power-based partner behaviors in supply chains has not previously been discussed.
\end{abstract}

Key Words: Buyer-supplier relationships; Power; Boundary-spanners; Cultural intelligence; National culture; Organizational culture 


\section{Introduction}

Global supply chains (GSCs) consist of a "full range of activities, including coordination, that are required to bring a specific product from its conception to its end use and beyond" (Gibbon \& Ponte, 2005, p. 77). Thanks to economic and technological drivers and enablers such as globalization, containerization, and communication technologies, a substantial share of buyersupplier relationships is international (Fang, Schei, \& Selart, 2018). Pivotal elements in the study of GSCs concern how GSCs are coordinated and managed across borders and how power dynamics fit into this picture (Gereffi, Humphrey, \& Sturgeon, 2005; Hult, 2004). Supply chain internationalization means that buyers and suppliers are compelled to operate in cross-cultural contexts (Ang \& Inkpen, 2008; Moon, 2010).

Following over 50 years of research on power in distribution channels and supply chains, one could suppose that there would be no new avenues for power research. However, the past several years have proven this supposition wrong as researchers shifted from focusing on sources, bases, and forms of power (French \& Raven, 1959; Gaski, 1984; Hunt \& Nevin, 1974) to novel approaches toward power such as power priorities (Meehan \& Wright, 2013), coalition behavior of weaker players in triads (Bastl, Johnson, \& Choi, 2013), and power non-use (Crook, Craighead, \& Autry, 2017).

Recently, Gölgeci, Murphy, and Johnston (2018) provided a template for understanding how supply chain partners' power-dependence conditions affect their decisions in applying various power-based behaviors toward one another, along with the effects of these behaviors on relational satisfaction. However, similar to earlier work (Bastl et al., 2013; Nyaga et al., 2013), they ascribe firm-level behavior choices and likely outcomes primarily to power symmetry/asymmetry and dependence without considering circumstances affecting behavioral choices by the boundary 
spanners of the respective supply chain firms. Perhaps this was due to Gölgeci, Murphy, and Johnston (2018) presuming that individual-level factors have little bearing on decisions made in applying power-based behaviors or in responses to these behaviors. However, the reality is that most supply chains span national borders (Gereffi et al., 2005) and, therefore, have boundary spanners of different national cultures making decisions as to the appropriateness of behaviors. Additionally, supply chain partners often function in light of different organizational cultures, again affecting their behavioral decisions. The result is that there are multiple culturally ascribed predispositions affecting perceptions of the appropriateness of power-based behaviors used toward GSC partners. These individual-level cultural differences (national cultures and organizational cultures of boundary spanners) have crucial effects on how boundary spanners choose powerbased behaviors directed toward GSC partners.

As this suggests, the boundary spanners of supply chain partners (i.e., marketing managers/sales representatives and supply chain managers/purchasing professionals that span organizational boundaries and represent their respective firms) are working with partners of varied nationalities, each with differences in "the collective programming of the mind" (Hofstede, 1994, p. 4). These differences can have dramatic effects on actions being taken by partners, along with responses made by partners of different nationalities. For instance, in their study of U.S. and Japanese distribution partners, Sakano and Johnson (1993) observe that national culture may affect interpretations of power bases, accompanied by responses that may be "interpreted as inappropriate." Fundamentally, boundary spanners in buyer-supplier relationships are continuously affected by their national culture programming, leading them to have predispositions about which power-based behaviors should be applied toward partners while also affecting how they interpret partner' behaviors toward them. 
In addition to national culture differences, differences in the organizational cultures of partners may have dramatic effects on actions and responses between partners, with these cascading to effects on relational and performance outcomes. Since organizational culture is "a set of shared assumptions and understandings about organizational functioning" (Deshpande \& Webster, 1989, p. 5), firms' logic, priorities, and strategies are deeply ingrained in the organizational culture that surrounds and is infused into employees. Thus, organizational culture affects choices of behaviors toward supply chain partners as well as how partner behaviors are perceived. Here, we develop arguments as to why and how boundary spanners' national and organizational culture play major roles in determining decisions regarding the application of power-based behaviors between global supply chain (GSC) partners.

Additionally, we argue that cultural intelligence (CQ) of the boundary spanners at partner firms moderates the relationship between culturally determined predispositions and power-based behaviors' exercise and response. CQ is defined as the capability to observe, interpret, and act upon unfamiliar and ambiguous social and cultural cues, i.e., being able to function and manage effectively in situations characterized by cultural diversity and novelty (Ang \& Inkpen, 2008; Shapiro, Ozanne, \& Saatcioglu, 2007). In effect, CQ enables boundary spanners to correctly read the context and then adapt the choice of power-based behaviors to the context, leading to more satisfying supply chain relationships (Gölgeci, Murphy, and Johnston 2018). Despite broad applicability (Ang, Van Dyne, \& Koh, 2006; Moon, 2010) and "efforts of organizations to improve their understanding of cross-cultural leadership abilities, scientific papers on cultural intelligence are surprisingly limited" (VanderPal, 2014, p. 121). Here, we bring much-needed attention to CQ's interplay between the effects of culture on predispositions toward power-based behaviors and the behaviors performed by boundary spanners in GSCs. 
In sum, our purpose is to bring greater attention to the influences of boundary spanners' national and organizational culture on power-based behaviors and responses being made by the boundary spanners of GSC partners and how these behaviors affect relational satisfaction. In so doing, we focus on individual boundary spanners and highlight cultural antecedents of predispositions toward applying power-based behaviors. We also discuss how CQ should lead boundary spanners to choose power-based behaviors not necessarily aligned with cultural tendencies and how the influence of CQ on behaviors should be associated with more positive relationship outcomes.

We make several contributions to the business-to-business marketing literature. First, marketing channels and supply chain management (SCM) research is much more likely to focus at the firm level than at the individual (boundary spanner) level. And yet, it is individuals making decisions. Second, very little research considers the effects of national culture on buyer-supplier relationships in GSCs (Ang \& Inkpen, 2008). However, the challenges facing today's supply chains are truly global, with GSCs often having partners spanning many national cultures. Since GSCs are the new norm, cross-cultural buyer-supplier relationships are to be expected, along with greater ambiguity as to the appropriate initiating and response behaviors to assure good outcomes (Griffith \& Myers, 2004). A buyer or a supplier in a culture-spanning relationship may find themselves behaving appropriately for their own cultural context but inappropriately from the perspective of their partner (Lohtia, Bello, \& Porter, 2009; Shapiro et al., 2007). Therefore, our first contribution is to discuss how boundary spanners' national culture affects the predispositions of power-based behaviors by GSC partners and the implications of these behaviors on relationship outcomes in global contexts. 
Also absent from the collective work on inter-organizational behaviors between GSC partners is the effect of organizational culture on decisions regarding how partners express power. Despite the possibility that national culture "constrains variation in organizational cultures" (Johns, 2006, p. 396) and evidence that business performance may tend to be stronger when "management practices are congruent with national culture" (Newman \& Nollen, 1996, p 773), Gerhart's (2009) review finds that most of the variation in organizational cultures is not explained by country. Thus, our second contribution is explicating how organizational culture affects the predispositions of power-based behaviors by GSC partners and the implications of these behaviors on relationship outcomes.

Finally, despite its potential relevance in explaining how GSC boundary spanners make power-based decisions and how these individuals respond to the power-based behaviors exerted by partners, CQ has been largely overlooked by marketing and SCM literature streams. This is because power in marketing and SCM mostly concentrates on economic and political factors at the firm-level in enacting inter-organizational power (Crook et al., 2017; Frazier, 1984; Meehan $\&$ Wright, 2013). As an adaptive capability (Magnusson et al., 2013) for effective management of cross-cultural relationships (Ang \& Inkpen, 2008; Moon, 2010), the effects of CQ on the relationship between culturally influenced predispositions and choices of power-based behaviors between GSC partners must be explicated. Thus, our final contribution is to explain the role of CQ as a moderating factor affecting expected culturally determined predispositions toward powerbased behaviors and power-based behaviors exerted by GSC boundary spanners and the acceptance of power-based behaviors exerted by partners.

\section{Theoretical background}


We draw on marketing and management research on culture (e.g., Deshpande \& Webster, 1989; Earley \& Ang, 2003; Hofstede, 2001), inter-organizational strategy (e.g., Beugré \& Acar, 2008; Heide, Wathne, \& Rokkan, 2007), and power (e.g., Gaski, 1984; Hunt \& Nevin, 1974) to advance understanding of the role culture plays in power-based behaviors exerted by GSC partners. We focus on boundary spanners, the organizational members who link their organization with the external environment (Williams, 2002). They typically are buyers in purchasing firms and sales and customer support managers of suppliers. Buyer-supplier relationships are built and sustained by individuals who span inter-organizational boundaries (Chakkol et al., 2018). Boundary spanners develop, facilitate, and sustain buyer-supplier relationships using practices such as negotiating with clients, leading innovation projects, communicating with SC partners, or contracting with suppliers (Korschun, 2015). In line with their fundamental tasks, boundary spanners are often required to possess the ability to engage with others and deploy effective relational and interpersonal competences (Williams, 2002).

We begin by discussing power-based behaviors exerted by supply chain partners. Power dynamics between partners are central to actions taken, how actions are interpreted, and choices of responses, with resultant effects on buyer-supplier relationships (Frazier, 1984; Hunt \& Nevin, 1974; Sakano \& Johnson, 1993). This is followed by discussing cultural dynamics affecting decisions made by boundary spanners of GSC partners. Absent awareness or concern for the national and organizational culture characteristics of individuals representing GSC partners, boundary spanners surely find themselves taking actions at times that are received by partners with surprise or even resentment. In turn, these actions could unnecessarily harm relationships, adversely affecting performance outcomes as well. Despite the fact that culture and power are in 
continuous interplay affecting GSC behaviors, they have received relatively little simultaneous attention in GSC literature (Ryu et al., 2008).

\subsection{Power-based behaviors in global supply chains}

Power is defined broadly as one firm's ability to influence the perceptions, behavior, and/or decision making of members of another firm (Frazier, 1984). Power influences both the power holder and the party that is subjected to power (Sturm \& Antonakis, 2015). At the epicenter of power is having discretion (agency) to act and the means to enforce one's will (Sturm \& Antonakis, 2015). Maloni and Benton (2000) articulate the role of power and power sources (reward, coercive, expert, referent, legitimate, legal legitimate; c.f. French and Raven 1959) in supply chains:

Power plays a significant role in the supply chain, and the different sources of power have contrasting effects upon inter-firm relationships in the chain. Thus, both the power source and the power target must be able to recognize the presence of power, then reconcile supply chain strategy for power influences (p.23).

The authors further comment that the appropriate use of power can strengthen relationships and enhance supply chain performance while exploitation through power misuse can have the opposite effects. These effects relate to both mediated power (a source of power applied by a power holder such as conferring rewards or coercion via threats) and non-mediated power (sources of power such as expert power that a partner may be willingly or gratefully influenced by). Benton and Maloni's (2005, p. 18) study of power and buyer/seller relationships in the automobile sector "highlights the importance of power awareness as well as recognition of power as a valuable approach for increasing the satisfaction of the entire supply chain.” Benton and Maloni (2005) assert that participants must understand and judiciously apply power to realize gains from positive bases and to reduce possible harms from negative bases. They conclude by arguing that "power- 
satisfaction relationships must become a prominent part of supply chain strategy" (p.18) and that for supply chain research to be realistic, the influences of power must be considered.

As discussed by Gölgeci et al. (2018), power-based behaviors are the behavioral enactment of power differentials between two members in a supply chain. They explain the way supply chain partners' power-dependence conditions are associated with inter-firm behaviors leading to varying levels of relational satisfaction. Consisting of dominance (amicable/aggressive), egalitarian, and submissive (willing/resentful) behaviors, power-based behaviors reflect the extent and nature of power exertion between initiating and responding partners. Power-based behaviors are especially relevant for GSCs engaged in complex collaborative projects, R\&D relationships, and strategic alliances, among others, where dependencies and transaction complexity are relatively high (Gereffi et al., 2005), as these require substantial inter-firm engagement including negotiations, collaborations, relationship development, and enforcement mechanisms.

In GSCs, partners have preferences toward power-based behaviors determined by factors including the organizational culture guiding the actions taken by the firm and national cultures of boundary spanners at each firm (Magnusson et al., 2013). There is a considerable likelihood that cultural differences affect the ability of GSC partners to effectively engage power-based behaviors toward one another that result in healthy buyer-seller relationships. While power research generally focuses on the exchange dynamics between two or more interacting entities (Gaski, 1984; Nyaga et al., 2013; Ryu et al., 2008), with GSCs the cultural differences between the partners must thus be an additional consideration. This is why organizational and national culture, forces determining the way power is understood and exercised by partners in GSCs (Gereffi et al., 2005), are central to this discussion.

\subsection{Culture and GSC buyer-supplier relationships}


Culture shapes managerial sense-making and behavior (Büschgens, Bausch, \& Balkin, 2013; Hofstede, 2001; Hofstede et al., 2010). Culture is a complex, personal, and multifaceted concept (Möller \& Svahn, 2004) lacking a single, agreed-upon definition (Voldnes, Grønhaug, \& Nilssen, 2012). Here, we view culture as "a set of values that are shared in a given social group and distinguish this group from others" (Beugelsdijk, et al. 2017, p. 31). Cultural frames, values, and beliefs are powerful forces in shaping individual's perceptions, predispositions, and behaviors (Gelfand, Nishii, \& Raver, 2006; Hofstede, 1980; Voldnes et al., 2012), with firms reflecting their cultural patterns as they transact business across organizational and national boundaries (Ryu et al., 2008).

Among differences, it is not hard to see why issues related to culture matter. GSC partners often have boundary spanners of diverse cultures. These boundary spanners likely choose powerbased behaviors aligned with their cultural norms (Ryu, Aydin, \& Noh, 2008), as culture is a pivotal source of individuals' attitudes, values, and behavior (Gulev, 2009; Hofstede et al., 2010; Sasaki \& Yoshikawa, 2014; Taras, Kirkman, \& Steel, 2010). For instance, in China and Japan culturally-embedded concepts such as Chinese guanxi (Xue et al., 2018) and Japanese keiretsu (Samaha, Beck, \& Palmatier, 2014) are part of the essential working knowledge of practitioners managing buyer-supplier relationships in these countries. In addition to national culture differences, organizational culture influences the way GSCs are governed and how an individual views, interprets, and exercises power (Ryu et al., 2008).

There are complex, interpersonal relationships between GSC' members spanning organizational boundaries (Chakkol et al., 2018). Boundary spanners play a substantial role in organizational performance based on the relationships they build with external actors (Korschun, 2015). Boundary-spanning actors involved in managing international buyer-supplier relationships 
are usually from different national cultures (Lohtia et al., 2009; Mehta et al., 2006). Their mindsets, worldviews, behaviors are shaped by their past and present cultural experiences. In a similar vein, organizational culture affects the way boundary spanners view and interact with external actors in the social landscape through individual filtering mechanisms such as boundary spanners' organizational identification (Korschun, 2015). This reality influences buyers' and suppliers' expectations and behavior and thereby, satisfaction with their relationships (Voldnes et al., 2012).

In sum, boundary spanners of diverse national and organizational cultures interact with each other as part of firms' GSC operations, with culture influencing decisions being made and resultant buyer-supplier relationships (Samaha et al., 2014; Xue et al., 2018). This means that cultural effects on how GSC boundary spanners engage with one another must be understood, thereby giving partners the ability to make power-based behaviors choices that improve the chance of gaining healthy relationships and positive GSC performance.

There are many national culture theories/tools including Hofstede's 6 dimensions model, Hall's High/Low Context cultures, Kluckhohn and Strodtbeck's value orientations toward universal problems, and GLOBE (The Global Leadership and Organizational Behavior Effectiveness Research Program) which seeks to understand universal as opposed to nationspecific leader attributes, behaviors, and practices. Of these, Hofstede (1980) has provoked the most research attention, with his initial four (power distance, uncertainty avoidance, individualism/collectivism, masculinity/femininity) and now six dimensions (to include long-term orientation, indulgence) studied so often that meta-analyses have been used to understand the collective impact of hundreds of studies using Hofstede' national culture dimensions (Taras et al., 2010; Taras, Steel, \& Kirkman, 2012), 
Here, we provide propositions as to the effects Hofstede's initial four national culture dimensions (power distance, masculinity/femininity, individualism/collectivism, uncertainty avoidance) each have on predispositions of GSC boundary spanners toward applying particular power-based behaviors. These dimensions have been the most widely studied of Hofstede's six dimensions ${ }^{1}$. We follow this with a discussion of organizational culture's effects on these predispositions using the flexibility-control and internal-external axes from the competing values framework (Quinn \& Rohrbaugh, 1983).

\section{The Effects of Culture on Power Behaviors and Relationship Outcomes in Supply Chains}

Our central assertion is that boundary spanners on both sides of a GSC relationship make powerbased decisions through national and organizational cultural lenses, with cultural intelligence of the boundary spanners affecting decisions and interpretations of partner' behaviors (Figure 1). Our resulting propositions, therefore, apply both to actions and responses of partners in global supply chains.

\section{Insert Figure 1 here}

\subsection{The cultural values of boundary spanners and their impact on power-based behaviors}

Introduced earlier, national culture is values, beliefs, and norms acquired primarily unconsciously during the early phase of individuals' life (Hofstede, 1980). It denotes a distinct, enduring pattern of behavior and personality characteristics (Doney, Cannon, \& Mullen, 1998) shared among a populace, and it is an essential informal institution (Deephouse, Newburry, \& Soleimani, 2016). It prescribes particular behaviors and proscribes other behaviors through rituals that reflect, maintain, and communicate cultural values (Ren \& Gray, 2009). It may vary within national boundaries

\footnotetext{
${ }^{1}$ Although associated with considerably less research, we recognize that the two newer dimensions (long-term orientation, indulgence) may also have relevance. In the conclusions section, we offer a few reflections about these dimensions, encouraging researchers also consider how these dimensions might help in understanding GSC behaviors between partners.
} 
depending on demographic and geographic diversity (Lenartowicz \& Roth, 2001) as well as change over time (Sasaki \& Yoshikawa, 2014).

National culture influences boundary spanners' perceptions and sense-making, thereby affecting managerial decision making and activities (Liang, Kale, \& Cherian, 2014). For instance, Doney et al. (1998) use Hofstede's culture dimensions (power distance, uncertainty avoidance, collectivism/individualism, masculinity/femininity) to show how culture can be used to anticipate differences in how inter-firm trust building occurs. As they articulate, it may be more likely that trust is formed when there is congruence in cultural characteristics and that when congruence is lacking there can be a "virtual collapse of the trust-building mechanism."

The study by Zhao et al. (2008) is one of very few SCM papers recognizing that national culture may affect power - relationship outcomes. They articulate why different power sources have differing effects on normative and instrumental relationship commitment while using power distance and collectivism to understand why supply chain participants in China and the U.S. might have sources of power "play(ing) a very different role in Chinese culture, compared with Western cultures" (p. 382). They further assert that "national culture may play an important role in SC power" (Zhao et al., 2008, p. 370).

Here, we similarly turn to Hofstede (2001) for discussing why - and in what manner - GSCs power-based behaviors and interpretations of partner behaviors are shaped by the national culture of the boundary spanners involved. We use Hofstede for the discussion because its validity, reliability, and usefulness have been confirmed over several decades and in a wide variety of settings and it is the most widely applied national culture framework (Kirkman, Lowe, \& Gibson, 2006; Taras et al., 2010). The hundreds of studies relying on Hofstede have led to numerous reviews (Deephouse et al., 2016; Hofstede, 2001; Nakata \& Sivakumar, 1996), with Kirkman et 
al. (2006, p. 285) asserting that Hofstede's classification provides "the most influential of cultural classifications." Although deficiencies in the model have been voiced, ranging from questioning its predictive ability, a lack of coherence in some dimensions, and some dimensions being artifacts of Hofstede's data set (Minkov, 2018), the significance of Hofstede's national culture dimensions in understanding business behavior across cultures cannot be overstated.

Next, we articulate how each of Hofstede's (1980) original four dimensions of national culture - power distance, masculinity, individualism, and uncertainty avoidance - leads to tendencies toward dominance, egalitarian, or submissive behaviors by GSC partners and the likely effects of these behaviors on partners depending on their cultural preferences. We then discuss how organizational culture influences these behavioral choices and outcomes. We then introduce cultural intelligence (CQ), discussing how boundary spanners with high CQ seem likely to make power-based behavior choices, along with how they respond to the power-based behaviors of partners, in ways that lead to more positive relationship outcomes.

Power distance refers to the extent to which one accepts and acts upon the notion that power in institutions and organizations is distributed unequally (Hofstede, 2001). The core premise of power distance concerns the perception and handling of inequalities between interacting parties. People in high power distance societies often follow hierarchy rigidly, emphasize authority and control, tend to centralize decision-making, and do not typically follow participative management practices (Shankarmahesh, Ford, \& Latour, 2003). It further seems that higher power distance cultures are more receptive to forming status-based relationships (Samaha et al., 2014). For instance, China is culturally a high power distance society (Hofstede \& Bond, 1988). High power distance means the less powerful members of organizations accept and expect that power is distributed unequally and view power imbalance between interacting parties as legitimate. 
Additionally, role compliance and adaptation are the focal issues that support the relationship web surrounding an individual. On the other hand, boundary spanners that are low in power distance emphasize equality, refraining from overt power exercise, and tend toward consultative decisionmaking (Wuyts \& Geyskens, 2005).

By extension, power distance might be reflected in the extent to which a GSC boundaryspanning manager believes that more powerful firms should have more say than their less powerful partners (Wuyts \& Geyskens, 2005), thus affecting tendencies toward using and, conversely, receptivity toward the application of dominance, egalitarian, and submissive partner behaviors. Consequently, GSC boundary spanners belonging to cultures with low power distance will focus more on equity, participation, solidarity, relationship maintenance, and fairness (Shankarmahesh et al., 2003). Meanwhile, boundary spanners belonging to cultures with high power distance will resort to dominance behaviors such as control, centralization, privilege maintenance, and the use of power exertion to influence their partners (Shankarmahesh et al., 2003) while also being more receptive to these behaviors by partners.

In sum, when boundary spanners are from high power distance cultures, those that are more powerful will be more likely to apply dominance behaviors, as this is a natural cultural tendency toward weaker partners. Meanwhile, partners with weaker power positions in the dyad will tend to be accepting of dominance behaviors by more powerful partners, using submissive behavior as a matter of course. However, when boundary spanners are in low power distance cultures, they may tend toward egalitarian behaviors regardless of their power position as these behaviors are more in line with their cultural values. 
Proposition 1a: The higher the power distance of the boundary spanner, the greater the predisposition toward performing dominance behaviors and responding to dominance behaviors through willing submissiveness.

Proposition 1b: The lower the power distance of the boundary spanner, the greater the predisposition toward performing egalitarian behaviors.

Masculinity/femininity refers to the extent that aggressiveness, competition, and acquiring material possessions are valued over harmony, nurturance, consensus making, and caring for others (Feldman \& Bolino, 1999). In masculine societies, "tough" masculine values of individual competence, achievement, and material success are emphasized over "soft" feminine values of cooperation, modesty, participation, and caring for the other (Lohtia et al., 2009). Highly masculine societies exhibit assertiveness and contentiousness (Shankarmahesh et al., 2003), while feminine societies focus on friendship, justice, abstinence from self-serving behavior, egalitarianism, and compassion (Beugré \& Acar, 2008; Doney et al., 1998). Despite these differences, Samaha et al. (2014) find that masculinity has "little impact on the effectiveness of relationship-building strategies." Even so, the markedly different attitudes represented by masculinity/femininity seem likely to affect preferences boundary spanners have in initiating various power-based behaviors and the behaviors used in response to partners' actions.

Drawing on the substantial evidence of the key characteristics of masculinity and femininity, it seems that boundary spanners from masculine societies will prefer using dominance behaviors. This is because dominance behaviors offer an excellent fit to aggressive, assertive, self-centered, and control and achievement-oriented style of governing buyer-supplier relationships that seem suited to masculinity. Meanwhile, weaker partners in high masculinity societies will tend to respond to dominance behaviors either contentiously with dominance responses or in a resentfully 
submissive way, because while they can acknowledge the implications of negative power balance, their natural tendencies favor dominance behavior.

Boundary spanners from feminine societies are likely to choose egalitarian behaviors when dealing with SC partners because they value equitable, collaborative, participative, mutually beneficial, and trust building relationship management (Doney et al., 1998; Samaha et al., 2014). Additionally, when these boundary spanners find themselves in weaker positions vis-à-vis their partners, they will be more accepting of dominance behaviors. In this manner, they will be more willing to perform submissive behaviors, particularly if their more powerful partner uses amicable dominance behaviors rather than aggressive dominance behaviors (Gölgeci et al. (2018).

Proposition 1c: The higher the masculinity of the boundary spanner, the greater the predisposition toward performing dominance behaviors and lesser the predisposition toward performing willing submissive behaviors.

Proposition 1d: The higher the femininity of the boundary spanner, the greater the predisposition toward performing and accepting equalitarian behaviors as well as willing submissive behaviors.

Individualism refers to "societies in which the ties between individuals are loose: everyone is expected to look after himself or herself and his or her immediate family" while collectivism as its opposite pertains to societies "in which people from birth onward are integrated into strong, cohesive in-groups...that continue to protect them in exchange for unquestioning loyalty" (Hofstede, 2011; p. 11). The widespread implications of individualism/collectivism have resulted in numerous articles, with a meta-analysis focused solely on this dimension (Sama \& Papamarcos, 2000). Another meta-analysis (Marcus \& Le, 2013) reports on the positive associations collectivism has with cooperative behavior at the individual level (they also report on studies focused on organizational and societal levels). By extension, boundary spanners of higher 
collectivism might be expected to seek cooperative relationships with partners. Accomplishing greater cooperativeness would seem to require boundary spanners to engage in particular powerbased behaviors that signal a preference for cooperation. If so, it seems likely that boundary spanners with high collectivism would more likely use amicable dominance behaviors or egalitarian behaviors (Gölgeci et al. (2018)) or more willingly respond with submissive behaviors to a dominating partner as these signal desires for cooperativeness.

Meanwhile, boundary spanners with greater individualism, possessing stronger desires to "look after oneself" to the exclusion of concerns for others, may be less interested in signaling cooperativeness, let alone having an interest in long term relationship building. The impact of individualism on relationship outcomes is profound, with individualism dampening "the effectiveness of many relationship-building strategies...as well as the effect of relationships on performance" (Samaha et al., 2014; p. 89). Also, high individualism cultures have greater difficulty in forming long-term socially bonded relationships. This suggests that boundary spanners with high individualism would be more inclined to use aggressive dominance behaviors when it suits their purpose since concerns for the consequences of these behaviors on the relationship are secondary to attaining immediate goals. It further suggests that these boundary spanners would be more likely to resent dominance behaviors by others, seeing these behaviors as forceful manipulations used in advantage seeking by their partners.

Proposition 1e: The higher the individualism of the boundary spanner, the greater the predisposition toward performing dominance behaviors while also having a greater predisposition to responding to dominance behaviors with resentful submissive behaviors. 
Proposition 1f: The higher the collectivism of the boundary spanner, the greater the predisposition toward performing amicable dominance and egalitarian behaviors while also having a greater predisposition to responding with willing submissive behaviors.

Lastly, uncertainty avoidance "deals with a society's tolerance for ambiguity. It indicates to what extent a culture programs its members to feel either uncomfortable or comfortable in unstructured situations" (Hofstede, 2011; p. 10). When engaged with partners from uncertainty avoidance cultures, Samaha et al. (2014) suggest that relationships are easier to form when activities reduce uncertainty. Reducing uncertainty requires behaviors that assure control and stability. Boundary spanners from high uncertainty avoidance nations are, therefore, unlikely to be tolerant of unpredictable, ambiguous, or undefined situations in their GSCs (Wuyts \& Geyskens, 2005). As a result, they require from their partners' predictability, uniformity, compliance, stability, and abstinence from unexpected ideas (Lohtia et al., 2009). Thus, when a more powerful partner has a boundary spanner from a high uncertainty avoidance culture, there is a likely preference for tight control over partners, making it more likely to use dominance behaviors to reduce uncertainty. Similarly, when a boundary spanner has high uncertainty avoidance and is in a weaker power position, they would prefer receiving these dominance behaviors, willingly being submissive in their response. That is, these submissive behaviors may be a natural inclination by weaker partners from high uncertainty avoidance cultures as it provides more certainty that their response satisfies the expectations of the partner to complete requirements as demanded. Even when there is relative power balance between partners, there might be a preference for each party to take turns in using amicable dominance behaviors, providing certainty as to expectations and thus provoking willing submissive responses (Gölgeci et al., 2018). 
Boundary spanners with low uncertainty avoidance are likely to accept uncertainties and risks more easily, leverage them as an opportunity, be open to new ideas, and show greater tolerance of various opinions and behaviors, including dissident ones (Lohtia et al., 2009; Shankarmahesh et al., 2003). Since boundary spanners from low uncertainty avoidance cultures are more comfortable with ambiguity, they can give greater decision-making roles to their partners. Therefore, egalitarian behaviors can be comfortably used. Also, a stronger partner, although perfectly capable of asserting dominance behaviors over the weaker partner, would instead more comfortably choose egalitarian behaviors. Although this opens the door to greater uncertainty of partner' response, the more powerful partner would accept this uncertainty, allowing their partner to have greater leeway in response. In sum, it is plausible that dominance and accompanying submissive behaviors work well with boundary spanners from high uncertainty avoidance cultures, while egalitarian behavior may be more appealing to boundary spanners of low uncertainty avoidance cultures.

Proposition 1g: The higher the boundary spanner's uncertainty avoidance, the greater the predisposition to perform and accept amicable dominance and willing submissive behaviors.

Proposition 1h: The lower the boundary spanner's uncertainty avoidance, the greater the predisposition to perform and accept egalitarian behaviors.

\subsection{Boundary spanners' organizational culture and power-based behaviors in GSCs}

Deshpandé, Farley, and Webster (1993; p. 4) define organizational culture as "the pattern of shared values and beliefs that help individuals understand the organizational functioning and that provide norms for behavior in the organization". Organizational culture constitutes the norms prescribing and sanctioning intra- and inter-organizational behaviors and the values in which the norms are embedded (Beugelsdijk, Koen, \& Noorderhaven, 2009). Organizational culture, 
therefore, plays a role in firm behavior, including behaviors in inter-organizational settings (Beugelsdijk et al., 2009). We expect that SC boundary spanners of partner firms, steeped in their respective organizational cultures, have resultant preferences for applying power-based behaviors toward a partner. Additionally, how a partner firm interprets and responds to partner' behavior is through the lens of the boundary spanner's organizational culture.

In what is referred to as a competing values framework, Quinn \& Rohrbaugh (1983) propose that the position of the firm can explain the firm culture and resultant behaviors along axes of flexibility-control and internal-external. Using these axes, the four resultant quadrants are labeled: group or human relations model (clan; flexible/internal), developmental or open system model (adhocracy; flexible/external), hierarchy or internal process model (internal/control), and rational goal model (market; external/control). The competing values framework has been widely studied and is considered influential, explaining the organizational culture of any firm. A recent meta-analysis by Büschgens et al. (2013) of 43 studies finds that Quinn and Rohrbaugh's Competing Values Framework provides a meaningful structure of the ideational aspects of organizational culture. Most organizations are a mixture of these four types; it is not uncommon to see the dominance of one form over others (Deshpandé \& Farley, 2004).

A firm's organizational culture has implications for how the firm and its boundary spanners engage with GSC partners (Deshpande \& Webster, 1989). For instance, while a GSC partner may possess the means to use dominance behaviors toward its partners, their organizational culture may be such that they tend toward using egalitarian behaviors. Instances, where this may occur, are when a partner has culture classified as developmental or open system (adhocracy; flexible/external), where the means to attain goals tends toward flexibility and readiness to pursue opportunities. This orientation implies that firms seek effectiveness via being dynamic, adaptable, 
and organic. This occurs by exhibiting partnering, autonomy, and "we-ness" (Cameron \& Quinn, 2011). Likewise, adhocracy cultures tend toward dynamism, creativity, entrepreneurship, and risktaking (Cameron \& Quinn, 2011; Deshpandé \& Farley, 2004). Naturally, boundary spanners from firms with this orientation might prefer egalitarian behaviors, since these behaviors are intended to provoke/encourage similar behaviors from their GSC partners.

Alternatively, some firms have cultures driven toward stability and control. These firms tend to be a hierarchy or internal process form (internal/control), using information management and communications to assure stability by controlling partners as a means to gain desired outcomes. Hierarchy-focused organizational cultures are characterized by rules, authority, and formal structures (Cameron \& Quinn, 2011; Deshpandé \& Farley, 2004). They enforce rules by monitoring behavior (Dwyer, Richard, \& Chadwick, 2003) while using incentives and threats as control mechanisms while simultaneously creating competition between their units and suppliers (Puranam, Gulati, \& Bhattacharya, 2013). Consistent with these themes, hierarchy-driven firms may choose dominance power-based behaviors to maintain control over partners, expecting submissive behaviors in return. Meanwhile, less powerful partners with similar stability and control-based hierarchy reflecting their organizational culture priorities are likely to find it agreeable to respond with submissive behaviors, as these behaviors are consistent with their perceptions of the relationship between the firms. It can also assure them that the dyad is working efficiently and with few tensions.

In sum, some organizational cultures (e.g., developmental or open system model/adhocracy cultures) produce tendencies for GSC boundary-spanning managers to use egalitarian behaviors toward business partners. At the same time, boundary spanners from firms of other organizational cultures (e.g., hierarchy or internal process) may have tendencies to feel that either dominance or 
submissive behaviors are the appropriate power-based behaviors depending on their power positions in GSCs.

Proposition 2a: The more a boundary spanner values hierarchy, the greater the likelihood that boundary spanners are predisposed to perform and accept dominance power-based behaviors by partners.

Proposition 2b: The more a boundary spanner values flexibility, the greater the likelihood that boundary spanners are predisposed to perform and accept egalitarian power-based behaviors.

\subsection{The moderating role of cultural intelligence}

The effects discussed above indicate that firms' national and organizational culture affect boundary spanners predispositions toward performing and accepting dominance, egalitarian, and submissive power-based behaviors. If a boundary spanner does not reflect on how these behaviors might be received by their culturally diverse partners, it seems likely that performed power-based behaviors will be aligned with these predispositions. Meanwhile, it seems apparent that tensions can arise between GSC partners due to culturally predisposed behaviors that are performed and then not favorably received by partner' boundary spanners with differing cultural predispositions. The reality is that "mismatches" can too easily occur, causing tensions that could have been avoided. The good news is that savvy boundary spanners should be able to adjust which powerbased behaviors are performed toward their culturally different partners, making their partner more receptive in response. It is also possible that a savvy partner receiving a power-based behavior inconsistent with their preferences can adjust how they view these behaviors, making the behavior more palatable. The mechanism for making these adaptations is cultural intelligence (CQ).

CQ refers to an individual's capability to function effectively across cultures -this can include national, ethnic, organizational as well as other types of culture (Van Dyne, Ang, \& 
Livermore 2010). This means that CQ affects how executives think as well as the actions executives then take as a result of their CQ-determined reflections. High CQ individuals devote time and effort to observe and understand other actor's culture(s), applying this learning to behavior. This enables high CQ individuals to overcome the challenges of cultural differences between themselves and others. As a skill set, CQ enables greater cognitive flexibility and equips individuals with cross-cultural competencies through an increased sense of awareness that GSC partners' motivations and behaviors are shaped by their cultural contexts (Ang et al., 2007; Magnusson et al., 2013). Accordingly, CQ has grown to be an essential concept for explaining how individuals deal with cultural diversity as well as predicting individual and group performance (Fang et al., 2018).

As Sharma, Tam, and Kim (2009) relate, succeeding in such activities as intercultural marketing and service encounters depend on the ability to think and act in appropriate ways with people from other cultures. This might be thought of as "reading the context correctly," with cultural intelligence being useful for adapting behaviors to context, thereby leading to more satisfying supply chain relationships (Gölgeci, Murphy, and Johnston 2018; p. 286). Boundary spanners with high CQ have been found to be more effective negotiators, more persuasive, and more focused (Imai \& Gelfand, 2010) as well as better at building comfortable cross-cultural interaction and role congruence (Sharma et al., 2009) in response to changing conditions and partner behaviors. Thus, CQ can be a critical capability for gaining trust, commitment, and cooperation, outcomes that are otherwise made difficult to attain due to cultural differences (Mehta et al., 2006).

CQ enables managers to deal with cultural differences, essentially regulating the actions taken by boundary spanners (Fang et al., 2018) in such a way that boundary spanners with high 
CQ become able and willing to adapt behaviors according to partners' cultural preferences. Thus, boundary spanners with high CQ are better able to address potential cultural challenges they may face in the management of relationships with their GSC partners, exhibiting greater ability to learn about, communicate effectively in, adapt to, and integrate with other cultures (Sharma et al., 2009). For example, a culturally-intelligent boundary spanner managing a buyer-supplier relationship with a Chinese partner may be more likely to invest time and effort to understand China's cultural norms, including high power distance, high collectivism, moderately high masculinity, and low uncertainty avoidance characterized by Chinese culture. By doing so, the culturally alert boundary spanner could do a better job of choosing power-based behaviors that will be well received by Chinese counterparts, even if these behaviors are not aligned with the boundary spanner's own preferences. To this, we should add that high CQ boundary spanners would also be more alert to Chinese guanxi, enabling the boundary spanner to build trust even in asymmetric relationships (Xue et al., 2018) by engaging in appropriate favors and empathy between the partners.

As these thoughts suggest, we anticipate that boundary spanners with high CQ are considerate and sensitive to the cultural mindset of their GSC partners. They use adaptive behaviors that are chosen to reflect the norms of the partner's culture better and, by doing so, gain positive partner response (Ang \& Inkpen, 2008; Moon, 2010) regardless of the power position between partners. The capabilities proffered by high CQ make it a pivotal factor to succeed in cross-cultural environments (Earley \& Ang, 2003), with Harvey and Richey (2001 p. 115) further asserting that "the need for a high cultural/social IQ is essential due to the potential variance in cultures among the organizations...in supply chains". In this vein, boundary spanners require a unique capability to effectively manage relationships between culturally diverse entities and leverage cultural diversity as an advantage (Alon \& Higgins, 2005). Boundary spanners also need 
to be politically and culturally savvy to avoid cultural discrepancies and conflicts. Thus, CQ emerges as a pivotal capability to face such challenges and interact successfully across cultures (Earley \& Ang, 2003).

In addition to the moderating role of $\mathrm{CQ}$ in affecting national culture determined predispositions toward applying particular power-based behaviors and the behaviors performed by GSC boundary spanners, we expect CQ to have a similar moderating effect on the organizational culture determined predispositions toward power-based behaviors and the performed behaviors relationship. Boundary spanners with high CQ are as likely to be as receptive to differences in organizational culture as they are to differences in national culture. By being more understanding and more accepting of why partners from other organizational cultures act and respond in specific ways (Thomas et al., 2008) boundary spanners with high CQ will be alert to the behaviors that should gain more favorable response by their partners. High CQ boundary spanners will also be less likely to either take offense or be unexpectedly hurt by the power-based behaviors of partners that are inconsistent with their culture-based preferences (Thomas et al., 2008). This is because the high CQ boundary spanner has an understanding of why their partner is using these behaviors.

In sum, boundary spanners with high CQ are more likely to factor in the organizational culture of their GSC partner into their decision-making. The result is that they can exhibit higher adaptability to power-based behavioral conditions (Magnusson et al., 2013), choosing powerbased behaviors that are aligned with their anticipations of gaining positive response by their culturally different partner(s). So, boundary spanners with high CQ should be more likely to apply dominance, egalitarian, or submissive behaviors that are anticipated to be aligned with the cultural norms of their GSC partners. These high CQ boundary spanners are more circumspect toward their own cultural biases, more competent in paying greater attention to the partner's culture, and more 
respectful and empathetic toward partners of different cultures (Sharma et al., 2009). They can, therefore, rise above the influences of their own national and organizational culture guided behavioral norms.

Proposition 3a: There tends to be alignment between GSC boundary spanners predispositions toward performing and accepting particular power-based behaviors and the performance of and acceptance of these same behaviors.

Proposition 3b: The cultural intelligence of GSC boundary spanners moderates the effect of national culture influenced predispositions toward performing and accepting power-based behaviors on the performance and acceptance of these behaviors. In particular, boundary spanners with high $C Q$ are less likely to be bound by national culture predispositions toward performing and accepting power-based behaviors.

Proposition 3c: The cultural intelligence of GSC boundary spanners moderates the effect of organizational culture influenced predispositions toward performing and accepting power-based behaviors on the performance and acceptance of these behaviors. In particular, boundary spanners with high CQ are less likely to be bound by organizational culture predispositions when performing and accepting power-based behaviors.

\subsection{Effects of Power-Based Behaviors on Relationship Outcomes}

Interspersed in the discussions of the main effects of national and organizational culture predispositions toward the appropriateness of various power-based behaviors and the moderating effect of CQ on choices of power-based behaviors performed were anticipated outcomes associated with these effects (Figure 1). As boundary spanners perform a power-based behavior toward a GSC partner, the boundary spanner at the partner' firm is also being influenced by their national culture as well as the organizational culture of their firm and, therefore, also possess 
predispositions toward power-based behaviors. When the power-based behaviors that follow are received by partner' boundary spanners possessing similar cultural norms the outcomes are generally thought to be favorable, as the receiving boundary spanner would consider the behavior "expected," i.e., matching what would typically be expected from their own cultural experience. At the same time, cultural mismatches would likely lead to power-based behaviors not aligned with expectations of the receiving boundary spanner. The result would be poor relationship outcomes. As Sirmon and Lane (2004, p. 309) aptly note, "national culture differences ...can challenge the development of successful relationships."

For certain, cultural variations among GSC partners may create daunting challenges for the management of international buyer-supplier relationships (Voldnes et al., 2012). The prospect of conflicts between partners may be amplified due to different cultural values, management styles, and governance mechanisms (Lin \& Wang, 2008) that may be unfamiliar. Also, preferences for relationship governance can diverge, with the potential for one partner to have a culturally acceptable preference for confrontation and forcing while the culturally distant partner prefers cooperation and compromise (Wang et al., 2005). Fundamentally, GSC partners of different cultural backgrounds may understand relationships and how partners should behave toward one another quite differently (Samaha et al., 2014; Xue et al., 2018).

When the discussion turned to CQ, it was evident that boundary spanners with high CQ are able and willing to be adaptive, choosing behaviors more accommodating to the understood cultural preferences of the boundary spanners of the partner firm while also interpreting behaviors of the partner through a cultural lens that results in greater acceptance and less resentment toward behaviors otherwise considered culturally offensive. This is because high CQ boundary spanners will understand the cultural drivers undergirding the behaviors of their partners, allowing them to 
more graciously accept behaviors that would be problematic for low CQ executives. The result will be a greater personal connection with GSC partners, one that is also more effective at communication (Sharma et al., 2009) and in building trust (Zander, Mockaitis, \& Butler, 2012). In sum, in addition to the moderating effects of CQ on the predispositions - to - performance and acceptance of power-based behaviors discussed in propositions $3 \mathrm{~b}$ and $3 \mathrm{c}$, we also expect a moderating effect of CQ on the performance of these behaviors - to - relationship outcomes. When power-based behaviors are aligned with cultural predispositions of the boundary spanners at the partner firm, relationship outcomes are expected to be favorable. At the same time, when these behaviors are not aligned with cultural predispositions of the boundary spanners at the partner firm we expect that the CQ of the individuals at the partner firm dampens the otherwise negative effect on relationship outcomes. CQ does this by enabling the boundary spanner to understand and even empathize with the cultural underpinnings leading their partner to use these behaviors. With CQ enabling greater acceptance of power-based behaviors, including behaviors not culturally aligned with predispositions, improved relationship outcomes between GSC partners should follow. So, we expect:

Proposition 4a: Performance of power-based behaviors aligned with the culturally framed predispositions of the boundary spanners at partner firms lead to more positive relationship outcomes.

Proposition 4b: The cultural intelligence of GSC boundary spanners receiving a power-based behavior from a partner moderates the link between power-based behaviors and relationship outcomes. It does so by reducing the negative effect of a mismatch between the individual's predispositions and the power-based behaviors applied by the partner. This is due to a higher 
likelihood of understanding and accepting the cultural underpinnings of why power-based behaviors are performed by their partner.

\section{Discussion and conclusions}

We describe how culture and cultural intelligence influences how boundary spanners of GSC partners engage with one another through the performance and acceptance of power-based behaviors. To do so, we bring a new perspective on the traditional power discourse found in SCM and marketing channels research by discussing national and organizational culture and the effects of culture on power-based behaviors used by GSC partners at the level of the individuals involved in these behaviors (boundary spanners) rather than at the firm level. We also add cultural intelligence of these boundary spanners to the discourse, thereby identifying a mechanism for improving GSC partner relationship outcomes. We make several key contributions to theory while providing several managerial implications.

\subsection{Theoretical implications}

Our work is a response to calls for more innovative research and theoretical development in business-to-business marketing and SCM research (Wilkinson \& Young, 2013) and, in particular, for gaining a better understanding of how and why power-based behaviors (Gölgeci et al., 2018) play out between GSC partners. We advance understanding of how power-based behaviors are initiated and responded to by concentrating on the boundary spanners who apply the behaviors, make sense of partner' behaviors, and respond to partner' behaviors. Collectively, we assert that boundary spanners' national and organizational culture determine predispositions about powerbased behaviors and that CQ affects the ensuing performance and acceptance of these behaviors. CQ thus leads to performing behaviors, interpreting behaviors, and responding to behaviors in ways that have positive effects on relationships between GSC partners. 
Until now, power-based behaviors have been examined at the firm level (Gölgeci et al., 2018), with most researchers not explicitly considering the boundary spanners making these behavioral choices. We assert that both national and organizational culture shape boundary spanners predispositions toward power-based behaviors, conditioning them to initiate, interpret, and respond to power-based behaviors in line with their cultural norms. Since boundary spanners of GSC partners often have different cultural norms, their predispositions and ensuing performance of power-based behaviors may be inconsistent with preferences of their partners, creating tensions between partners. These tensions can adversely affect relationships.

Once aware of the implications of culture on predispositions and in light of the advantages of having high cultural intelligence, GSC boundary spanners should realize the value of developing CQ; CQ enables boundary spanners to be cognizant of the advantages of not simply defaulting to predispositions in choosing behaviors or in interpreting the behaviors exerted by partners. In short, in addition to the main effects of culture on predispositions and ensuing performance of powerbased behaviors, the CQ of boundary spanners leads to adaptive practices in the application of power-based behaviors, thereby helping avoid problems with partners while assuring improved relationship outcomes. Thus, consistent with Moon's (2010) assertions, we contend that CQ is critical for managing international buyer-supplier relationships. In particular, firms whose boundary spanners have high CQ are likely to be more adept at choosing power-based behaviors that gain positive responses from partners of diverse national and organizational cultures while also being more receptive to partner behaviors inconsistent with their own preferences.

Firms with culturally adaptable boundary spanners perform better in the global marketplace (Paik \& Sohn, 2004). We contend that this is because the initiator of behaviors is less likely to be bound by their cultural tendencies, more likely to account for partner's cultural expectations, and 
better able to adapt choices of behaviors that can be expected to be well-received by their partners. Similarly, the culturally adept (high CQ) partner is more likely to be receptive to a partner's powerbased behaviors, even if a behavior is not considered appropriate to his/her own culture. Thus, the inclusion of CQ in our model has considerable merit, positioned properly between predispositions and performance/acceptance toward these behaviors, with CQ determining whether boundary spanners develop more effective patterns of the performance and acceptance of power-based behaviors. The result should be more positive relationship outcomes, including greater cooperation, inter-organizational trust, and satisfaction.

\subsection{Managerial implications}

GSC partners are undoubtedly more effective when they choose power-based behaviors that take into consideration not just their power positions but also the cross-cultural implications of powerbased behaviors on partners of differing national and organizational cultures. In a world where GSC boundary spanners work with counterparts of diverse national and organizational cultures, there are many challenges in choosing power-based behaviors that are most effective at growing partner' relationships and desired performance outcomes. This makes it essential to make informed decisions about the likely effects of the power-based behaviors on partners, as these behaviors have effects on partner responses. With the goal of becoming more prepared to build strong, successful relationships with GSC partners, a consciousness of culture may be the path to greater effectiveness.

Once supply chain executives realize the importance of CQ, it becomes imperative for firms to commit resources to assure high CQ among the boundary spanners representing their firms CQ may be a singularly capable means for creating long-term global buyer-supplier relationships. Developing boundary spanners' CQ entails deploying policies and procedures to foster CQ 
development and aligning human resource management policies to make this possible. Valuing CQ also encourages attracting, selecting, and retaining culturally intelligent employees. The result is that firms involved in GSC management are given a mechanism that puts an end to a potential blind spot in developing healthy relationships with culturally diverse partners.

\subsection{Research opportunities and additional considerations}

As discussed, there is considerable research conducted at the firm level but too little research conducted at the individual (boundary spanner) level when examining the effects of culture on GSC relationships. Our model and accompanying propositions challenges researchers to consider predispositions toward performing and accepting power-based behaviors as well as actual performance and acceptance of these behaviors. This enables researchers to properly examine the main effects of a boundary spanner's national and organizational culture on predispositions toward performing and accepting power-based behaviors while then examining whether our assertions concerning the moderating effect of $\mathrm{CQ}$ on the otherwise consistency expected between a boundary spanner's predispositions and the ensuing performance/acceptance of power-based behaviors. Intriguing opportunities thus emanate from our discussion and propositions.

The challenges of cross-cultural research, from the development of research questions to the design and execution of research methods, must be given careful consideration when researching this domain. It is evident that cross-cultural research poses many challenges, such as potential trade-offs between etic (from outside of the cultural group from the perspective of the observer) and emic (from within the cultural group, from the perspective of the subject) research approaches and issues in accounting for data equivalence (Hult et al., 2008). It will be appropriate to use a grounded theory approach as an initial way to develop the concepts we introduced. For this purpose, the interactions between boundary spanners of buyers and suppliers may be explored 
using interviews with boundary-spanning personnel and analytics similar to the approach used by Wilhelm et al. (2016). As qualitative studies reveal and clarify the domain, empirical studies can be used to evaluate contexts applicable to proposed relationships. Broadly, GSC studies are needed at the level of partner' dyads for examining power-based behaviors in cross-cultural business-tobusiness contexts. This should reveal valuable insights into the nature and dynamics of the application of power-based behaviors and the extent that cultural considerations are affecting decisions.

There are several additional considerations moving forward. First, while we pose national culture expectations using Hofstede's four most familiar dimensions, his two newer dimensions were not considered here. It has merit to reflect on these dimensions as to their possible effects on GSC partner behaviors. Also, Hofstede offers just one of several national culture frameworks that can be used (e.g., House et al., 2004; Schwartz, 2006). Additionally, despite its widespread use and acknowledged strength in capturing people's cultural value and their impact on behavior (Kirkman et al., 2006; Taras et al., 2010), Hofstede's typology of national culture is also subject to criticisms and shortcomings (Baskerville, 2003; Magnusson et al., 2008; Yaprak, 2008). Therefore, it may be useful to consider culture effects on supply chain relationships using other cultural typologies. Even so, Beugelsdijk et al. (2015; pg 223) find continuing relevance of Hofstede's culture index by affirming that "cultural differences between country pairs are generally stable."

An additional matter is that some scholars assert that organizational culture does not deviate much from national culture. Nelson and Gopalan (2003) relate that there is a "logical connection between national and organizational culture via individual socialization and institutional forms." Meanwhile, Gulev (2009) asserts that national and organizational cultures are not always 
isomorphic, and individuals may not always reflect the cultural values of their nation or organization. It is even possible that national and organizational cultural values change across times and contexts and exert conflicting influence on boundary spanners. Still, another consideration is whether cultural tightness is a factor affecting power-based behaviors by boundary spanners. Lee and Kramer (2016) suggest that organizational culture is less likely to deviate from national culture in tighter cultures rather than looser cultures. In part, this may be due to these societies placing greater emphasis on their cultural values, with less tolerance for behaviors that are divergent from cultural values and societal norms (Taras et al. (2010). These considerations should be part of future research.

We acknowledge that factors beyond national and organizational culture can shape powerbased behavior choices and the way these behaviors are exercised. For example, the nature of the exchange between buyers and suppliers (e.g., whether considered strategic or not for either or both parties) likely influences how boundary spanners apply power-based behaviors. Likewise, powerbased behaviors may be contingent on the nature of the exchange relationship such as whether the product or service is standard as opposed to being unique or customized. We also realize that firms' power positions can shift due to exigent external circumstances such as technology change or competitors entering or exiting markets. In response, the culture of the organization may have to change in order to cope with changes in power positions with supply chain members. For example, a manufacturing firm may be disrupted by the entry from a foreign competitor, being forced to realize it can no longer act with aggressive dominance behaviors toward partners since their power/dependence relationships have been altered. Finally, the boundary spanners choosing power-based behaviors are surely affected by other individual-level factors including personality 
and experience. These factors need to be considered and controlled for when examining the proposed relationships.

In conclusion, conceptualizing the effects of national and organizational culture on powerbased behaviors between partners in GSCs and CQ's ability to amplify or reduce these effects offers excellent potential for improved buyer-supplier relationships and performance. Our model and propositions address the need to attend to the complex and dynamic nature of cross-cultural buyer-supplier relationships as a means to assure effective GSC relationship management. 


\section{References}

Alon, I. and Higgins, J. M. (2005), "Global leadership success through emotional and cultural intelligences", Business Horizons, Vol. 48 No. 6, pp. 501-512.

Ang, S. and Inkpen, A. C. (2008), "Cultural intelligence and offshore outsourcing success: A framework of firm-level intercultural capability", Decision Sciences, Vol. 39 No. 3, pp. 337-358.

Ang, S., Van Dyne, L. and Koh, C. (2006), "Personality correlates of the four-factor model of cultural intelligence", Group \& Organization Management, Vol. 31 No. 1, pp. 100-123.

Ang, S., Van Dyne, L., Koh, C., Ng, K. Y., Templer, K. J., Tay, C. and Chandrasekar, N. A. (2007), "Cultural intelligence: Its measurement and effects on cultural judgment and decision making, cultural adaptation and task performance", Management and Organization Review, Vol. 3 No. 3, pp. 335-371.

Baskerville, R. F. (2003), "Hofstede never studied culture", Accounting, organizations and society, Vol. 28 No. 1, pp. 1-14.

Bastl, M., Johnson, M. and Choi, T. Y. (2013), "Who's seeking whom? Coalition behavior of a weaker player in buyer-supplier relationships", Journal of Supply Chain Management, Vol. 49 No. 1, pp. $8-28$.

Benton, W. and Maloni, M. (2005), "The influence of power driven buyer/seller relationships on supply chain satisfaction", Journal of Operations Management, Vol. 23 No. 1, pp. 1-22.

Beugelsdijk, S., Koen, C. and Noorderhaven, N. (2009), "A dyadic approach to the impact of differences in organizational culture on relationship performance", Industrial Marketing Management, Vol. 38 No. 3, pp. 312-323.

Beugelsdijk, S., Maseland, R., \& Van Hoorn, A. (2015). "Are Scores on Hofstede's Dimensions of

National Culture Stable over Time? A Cohort Analysis", Global Strategy Journal, 5(3), 223-240.

Beugelsdijk, S., Kostova, T., \& Roth, K. (2017). "An overview of Hofstede-inspired country-level culture research in international business since 2006". Journal of International Business Studies, 48(1), 30-47.

Beugré, C. D. and Acar, W. (2008), "Offshoring and cross-border interorganizational relationships: A justice model", Decision Sciences, Vol. 39 No. 3, pp. 445-468.

Büschgens, T., Bausch, A. and Balkin, D. B. (2013), "Organizational culture and innovation: A metaanalytic review", Journal of Product Innovation Management, Vol. 30 No. 4, pp. 763-781.

Cameron, K. S. and Quinn, R. E. (2011), Diagnosing and changing organizational culture: Based on the competing values framework, Jossey-Bass, San Francisco, CA.

Chakkol, M., Karatzas, A., Johnson, M. and Godsell, J. (2018), "Building bridges: Boundary spanners in servitized supply chains", International Journal of Operations \& Production Management, Vol. 38 No. 2, pp. 579-604.

Crook, T. R., Craighead, C. W. and Autry, C. W. (2017), "Hold back or held back? The roles of constraint mitigation and exchange diffusion on power "nonuse" in buyer-supplier exchanges", Journal of Supply Chain Management, Vol. 53 No. 2, pp. 10-21.

Deephouse, D. L., Newburry, W. and Soleimani, A. (2016), "The effects of institutional development and national culture on cross-national differences in corporate reputation", Journal of World Business, Vol. 51 No. 3, pp. 463-473.

Deshpandé, R. and Farley, J. U. (2004), "Organizational culture, market orientation, innovativeness, and firm performance: An international research odyssey", International Journal of Research in Marketing, Vol. 21 No. 1, pp. 3-22.

Deshpandé, R., Farley, J. U. and Webster, F. E. (1993), "Corporate culture, customer orientation, and innovativeness in Japanese firms: A quadrad analysis", Journal of Marketing, Vol. 57 No. 1, pp. 23-37.

Deshpande, R. and Webster, F. E. (1989), "Organizational culture and marketing: Defining the research agenda", Journal of Marketing, Vol. 53 No. 1, pp. 3-15.

Doney, P. M., Cannon, J. P. and Mullen, M. R. (1998), "Understanding the influence of national culture on the development of trust", Academy of management review, Vol. 23 No. 3, pp. 601-620. 
Dwyer, S., Richard, O. C. and Chadwick, K. (2003), "Gender diversity in management and firm performance: The influence of growth orientation and organizational culture", Journal of Business Research, Vol. 56 No. 12, pp. 1009-1019.

Earley, P. C. and Ang, S. A. (2003), Cultural intelligence: Individual interactions across cultures, Stanford business books, Stanford. CA.

Fang, F., Schei, V. and Selart, M. (2018), "Hype or hope? A new look at the research on cultural intelligence", International Journal of Intercultural Relations.

Feldman, D. C. and Bolino, M. C. (1999), "The impact of on-site mentoring on expatriate socialization: A structural equation modelling approach", International Journal of Human Resource Management, Vol. 10 No. 1, pp. 54-71.

Frazier, G. L. (1984), "The interfirm power-influence process within a marketing channel", Research in marketing.

French, J. R. P. and Raven, B. (1959), "The bases of social power", in Cartwright, D. (Ed.), Studies in social power. University of Michigan Press, pp. 150-167.

Gaski, J. F. (1984), "The theory of power and conflict in channels of distribution", Journal of Marketing, Vol. 48 No. 3, pp. 9-29.

Gelfand, M. J., Nishii, L. H. and Raver, J. L. (2006), "On the nature and importance of cultural tightnesslooseness", Journal of Applied Psychology, Vol. 91 No. 6, pp. 1225-1244.

Gereffi, G., Humphrey, J. and Sturgeon, T. (2005), "The governance of global value chains", Review of International Political Economy, Vol. 12 No. 1, pp. 78-104.

Gerhart, B. (2009), "How much does national culture constrain organizational culture?", Management and Organization Review, Vol. 5 No. 2, pp. 241-259.

Gibbon, P. and Ponte, S. (2005), Trading down: Africa, value chains, and the global economy, Temple University Press, Philadelphia, PA.

Griffith, D. A. and Myers, M. B. (2004), "The performance implications of strategic fit of relational norm governance strategies in global supply chain relationships", Journal of International Business Studies, Vol. 36 No. 3, pp. 254-269.

Gulev, R. E. (2009), "Are national and organizational cultures isomorphic? Evidence from a four country comparative study", Managing Global Transitions, Vol. 7 No. 3, pp. 259.

Gölgeci, I., Murphy, W. H. and Johnston, D. A. (2018), "Power-based behaviors in supply chains and their effects on relational satisfaction: A fresh perspective and directions for research", European Management Journal, Vol. 36 No. 2, pp. 278-287.

Harvey, M. G. and Richey, R. G. (2001), "Global supply chain management: The selection of globally competent managers", Journal of International Management, Vol. 7 No. 2, pp. 105-128.

Heide, J. B., Wathne, K. H. and Rokkan, A. I. (2007), "Interfirm monitoring, social contracts, and relationship outcomes", Journal of Marketing Research, Vol. 44 No. 3, pp. 425-433.

Hofstede, G. (1980), Culture's consequences: International differences in work-related values, Sage Publications, Inc, Newburry Park, CA.

Hofstede, G. (1994). "Management scientists are human", Management science, 40(1), 4-13.

Hofstede, G. (2001), Culture's consequences: Comparing values, behaviors, institutions, and organizations across nations, Sage Publications, Inc, Thousand Oaks, CA.

Hofstede, G. (2011), "Dimensionalizing cultures: The Hofstede model in context", Online readings in psychology and culture, Vol. 2 No. 1, pp. 8.

Hofstede, G. and Bond, M. H. (1988), "The Confucius connection: From cultural roots to economic growth", Organizational Dynamics, Vol. 16 No. 4, pp. 5-21.

Hofstede, G., Hofstede, G. J. and Minkov, M. (2010), Cultures and organizations: Software of the mind, McGraw-Hill New York, NY.

House, R. J., Hanges, P. J., Javidan, M., Dorfman, P. W. and Gupta, V. (2004), Culture, leadership, and organizations: The globe study of 62 societies, Sage, Thousand Oaks, CA.

Hult, G. T. M. (2004), "Global supply chain management: An integration of scholarly thoughts", Industrial Marketing Management, Vol. 33 No. 1, pp. 3-5. 
Hult, G. T. M., Ketchen, D. J., Griffith, D. A., Finnegan, C. A., Gonzalez-Padron, T., Harmancioglu, N., Huang, Y., Talay, M. B. and Cavusgil, S. T. (2008), "Data equivalence in cross-cultural international business research: Assessment and guidelines", Journal of International Business Studies, Vol. 39 No. 6, pp. 1027-1044.

Hunt, S. and Nevin, J. (1974), "Power in a channel of distribution: Sources and consequences", Journal of Marketing Research, Vol. 11 No. 2, pp. 186-193.

Imai, L. and Gelfand, M. J. (2010), "The culturally intelligent negotiator: The impact of cultural intelligence (CQ) on negotiation sequences and outcomes", Organizational Behavior and Human Decision Processes, Vol. 112 No. 2, pp. 83-98.

Johns, G. (2006), "The essential impact of context on organizational behavior", Academy of management review, Vol. 31 No. 2, pp. 386-408.

Kirkman, B. L., Lowe, K. B. and Gibson, C. B. (2006), "A quarter century of culture's consequences: A review of empirical research incorporating Hofstede's cultural values framework", Journal of International Business Studies, Vol. 37 No. 3, pp. 285-320.

Korschun, D. (2015), "Boundary-spanning employees and relationships with external stakeholders: A social identity approach", Academy of Management Review, Vol. 40 No. 4, pp. 611-629.

Lee, Y. and Kramer, A. (2016), "The role of purposeful diversity and inclusion strategy (PDIS) and cultural tightness/looseness in the relationship between national culture and organizational culture", Human Resource Management Review, Vol. 26 No. 3, pp. 198-208.

Lenartowicz, T. and Roth, K. (2001), "Does subculture within a country matter? A cross-cultural study of motivational domains and business performance in Brazil", Journal of International Business Studies, Vol. 32 No. 2, pp. 305-325.

Liang, B., Kale, S. H. and Cherian, J. (2014), "Is the future static or dynamic? The role of culture on escalation of commitment in new product development", Industrial Marketing Management, Vol. 43 No. 1, pp. 155-163.

Lin, X. and Wang, C. L. (2008), "Enforcement and performance: The role of ownership, legalism and trust in international joint ventures", Journal of World Business, Vol. 43 No. 3, pp. 340-351.

Lohtia, R., Bello, D. C. and Porter, C. E. (2009), "Building trust in US-Japanese business relationships: Mediating role of cultural sensitivity", Industrial Marketing Management, Vol. 38 No. 3, pp. 239252.

Magnusson, P., Westjohn, S. A., Semenov, A. V., Randrianasolo, A. A. and Zdravkovic, S. (2013), "The role of cultural intelligence in marketing adaptation and export performance", Journal of International Marketing, Vol. 21 No. 4, pp. 44-61.

Magnusson, P., Wilson, R. T., Zdravkovic, S., Xin Zhou, J. and Westjohn, S. A. (2008), "Breaking through the cultural clutter: A comparative assessment of multiple cultural and institutional frameworks", International Marketing Review, Vol. 25 No. 2, pp. 183-201.

Maloni, M. and Benton, W. (2000), "Power influences in the supply chain", Journal of Business Logistics, Vol. 21 No. 1, pp. 49-74.

Marcus, J. and Le, H. (2013), "Interactive effects of levels of individualism-collectivism on cooperation: A meta-analysis", Journal of Organizational Behavior, Vol. 34 No. 6, pp. 813-834.

Meehan, J. and Wright, G. H. (2013), "Power priorities in buyer-seller relationships: A comparative analysis", Industrial Marketing Management, Vol. 42 No. 8, pp. 1245-1254.

Mehta, R., Larsen, T., Rosenbloom, B. and Ganitsky, J. (2006), "The impact of cultural differences in U.S. Business-to-business export marketing channel strategic alliances", Industrial Marketing Management, Vol. 35 No. 2, pp. 156-165.

Minkov, M. (2018), "A revision of Hofstede's model of national culture: Old evidence and new data from 56 countries", Cross Cultural \& Strategic Management, Vol. 25 No. 2, pp. 231-256.

Moon, T. (2010), "Organizational cultural intelligence: Dynamic capability perspective", Group \& Organization Management, Vol. 35 No. 4, pp. 456-493.

Möller, K. and Svahn, S. (2004), "Crossing east-west boundaries: Knowledge sharing in intercultural business networks", Industrial Marketing Management, Vol. 33 No. 3, pp. 219-228. 
Nakata, C. and Sivakumar, K. (1996), "National culture and new product development: An integrative review", Journal of Marketing, Vol. 60 No. 1, pp. 61-72.

Nelson, R.E. and Gopalan, S. (2003), "Do organizational cultures replicate national cultures? Isomorphism, rejection and reciprocal opposition in the corporate values of three countries", Organization Studies, Vol. 24 No. 7, pp. 1115-1151.

Newman, K. L. and Nollen, S. D. (1996), "Culture and congruence: The fit between management practices and national culture", Journal of international business studies, Vol. 27 No. 4, pp. 753 779.

Nyaga, G. N., Lynch, D. F., Marshall, D. and Ambrose, E. (2013), "Power asymmetry, adaptation and collaboration in dyadic relationships involving a powerful partner", Journal of Supply Chain Management, Vol. 49 No. 3, pp. 42-65.

Paik, Y. and Sohn, J. D. (2004), "Expatriate managers and MNC's ability to control international subsidiaries: The case of Japanese MNCs", Journal of World Business, Vol. 39 No. 1, pp. 61-71.

Puranam, P., Gulati, R. and Bhattacharya, S. (2013), "How much to make and how much to buy? An analysis of optimal plural sourcing strategies", Strategic Management Journal, Vol. 34 No. 10, pp. 1145-1161.

Quinn, R. E. and Rohrbaugh, J. (1983), "A spatial model of effectiveness criteria: Towards a competing values approach to organizational analysis", Management Science, Vol. 29 No. 3, pp. 363-377.

Ren, H. and Gray, B. (2009), "Repairing relationship conflict: How violation types and culture influence the effectiveness of restoration rituals", Academy of Management Review, Vol. 34 No. 1, pp. 105126.

Ryu, S., Aydin, N. and Noh, J. (2008), "A cross-national study of manufacturer's power structures and control mechanisms: The moderating effect of group orientation culture", Industrial Marketing Management, Vol. 37 No. 7, pp. 758-766.

Sakano, T. and Johnson, J. L. (1993), "The exercise of interfirm power and its repercussions in usJapanese channel relationships", Journal of Marketing, Vol. 57 No. 2, pp. 1-10.

Sama, L. M. and Papamarcos, S. D. (2000), "Hofstede's ic dimension as predictive of allocative behaviors: A meta-analysis", International Journal of Value-Based Management, Vol. 13 No. 2, pp. 173-188.

Samaha, S. A., Beck, J. T. and Palmatier, R. W. (2014), "The role of culture in international relationship marketing", Journal of Marketing, Vol. 78 No. 5, pp. 78-98.

Sasaki, I. and Yoshikawa, K. (2014), "Going beyond national cultures - dynamic interaction between intra-national, regional, and organizational realities", Journal of World Business, Vol. 49 No. 3, pp. 455-464.

Schwartz, S. H. (2006), "A theory of cultural value orientations: Explication and applications", Comparative Sociology, Vol. 5 No. 2-3, pp. 137-182.

Shankarmahesh, M. N., Ford, J. B. and Latour, M. S. (2003), "Cultural dimensions of switching behavior in importer-exporter relationships", Academy of Marketing Science Review, Vol. 3, pp. 1-17.

Shapiro, J. M., Ozanne, J. L. and Saatcioglu, B. (2007), "An interpretive examination of the development of cultural sensitivity in international business", Journal of International Business Studies, Vol. 39 No. 1, pp. 1-17.

Sharma, P., Tam, J. L. and Kim, N. (2009), "Demystifying intercultural service encounters: Toward a comprehensive conceptual framework", Journal of Service Research, Vol. 12 No. 2, pp. 227-242.

Sirmon, D. G., \& Lane, P. J. 2004. A model of cultural differences and international alliance performance. Journal of International Business Studies, 35(4): 306-319.

Sturm, R. E. and Antonakis, J. (2015), "Interpersonal power: A review, critique, and research agenda", Journal of Management, Vol. 41 No. 1, pp. 136-163.

Taras, V., Kirkman, B. L. and Steel, P. (2010), "Examining the impact of culture's consequences: A three-decade, multilevel, meta-analytic review of Hofstede's cultural value dimensions", Journal of Applied Psychology, Vol. 95 No. 3, pp. 405-439. 
Taras, V., Steel, P. and Kirkman, B. L. (2012), "Improving national cultural indices using a longitudinal meta-analysis of Hofstede's dimensions", Journal of World Business, Vol. 47 No. 3, pp. 329-341.

Thomas, D. C., Elron, E., Stahl, G., Ekelund, B. Z., Ravlin, E. C., Cerdin, J.-L., Poelmans, S., Brislin, R., Pekerti, A. and Aycan, Z. (2008), "Cultural intelligence domain and assessment", International Journal of Cross Cultural Management, Vol. 8 No. 2, pp. 123-143.

VanderPal, G. (2014). Global Leadership, IQ and Global Quotient. Journal of Management, 15(5), 120 134.

Voldnes, G., Grønhaug, K. and Nilssen, F. (2012), "Satisfaction in buyer-seller relationships-influence of cultural differences", Industrial Marketing Management, Vol. 41 No. 7, pp. 1081-1093.

Wang, C. L., Lin, X., Chan, A. K. and Shi, Y. (2005), "Conflict handling styles in international joint ventures: A cross-cultural and cross-national comparison", Management International Review, Vol. 45 No. 1, pp. 3-21.

Wilhelm, M. M., Blome, C., Bhakoo, V. and Paulraj, A. (2016), "Sustainability in multi-tier supply chains: Understanding the double agency role of the first-tier supplier", Journal of Operations Management, Vol. 41, pp. 42-60.

Wilkinson, I. F. and Young, L. C. (2013), "The past and the future of business marketing theory", Industrial Marketing Management, Vol. 42 No. 3, pp. 394-404.

Williams, P. (2002), "The competent boundary spanner", Public Administration, Vol. 80 No. 1, pp. 103 124.

Wuyts, S. and Geyskens, I. (2005), "The formation of buyer-supplier relationships: Detailed contract drafting and close partner selection", Journal of Marketing, Vol. 69 No. 4, pp. 103-117.

Xue, J., Lu, S., Shi, B. and Zheng, H. (2018), "Trust, guanxi, and cooperation: A study on partner opportunism in Chinese joint-venture manufacturing", Journal of Business \& Industrial Marketing, Vol. 33 No. 1, pp. 95-106.

Yaprak, A. (2008), "Culture study in international marketing: A critical review and suggestions for future research", International Marketing Review, Vol. 25 No. 2, pp. 215-229.

Zander, L., Mockaitis, A. I. and Butler, C. L. (2012), "Leading global teams", Journal of World Business, Vol. 47 No. 4, pp. 592-603.

Zhao, X., Huo, B., Flynn, B. and Yeung, J. (2008), "The impact of power and relationship commitment on the integration between manufacturers and customers in a supply chain", Journal of Operations Management, Vol. 26 No. 3, pp. 368-388. 


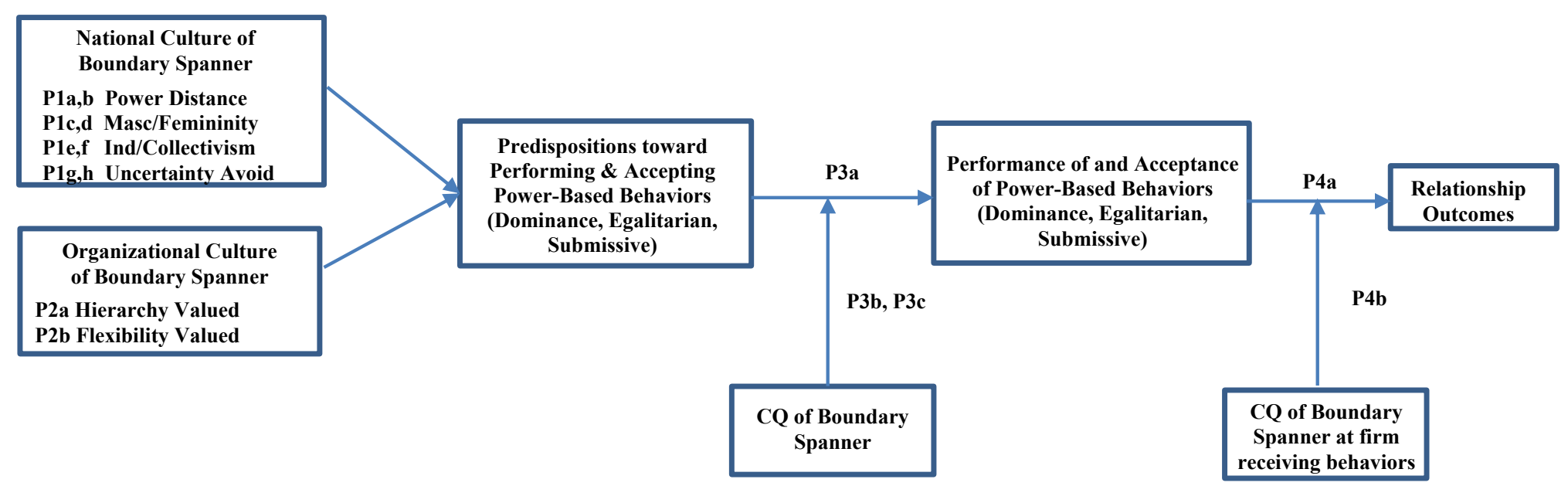

Figure 1: Cultural and CQ influences on power-based behaviors and relationship outcomes in international buyer-supplier relationships 